\title{
Soft contact lenses in cases of aphakia
}

\author{
D. LOBASGHER, J. GHASTON, J. MORRIS, AND M. RUBEN \\ Moorfields Eye Hospital, High Holborn, London, W.C.I
}

The use of hydrophilic acrylates (Polyнema) in the composition of contact lenses was first described by Wichterle and Lim (i960).

The development of a spun cast lens has taken several years. The basic technique by Wichterle has now been extended by the manufacturers, Bausch and Lomb. Whilst the low minus powers are available in more than one back curve fitting, the high minus and aphakic series have one basic fitting for each power. The aphakic lenses have reduced front optics to give a central thickness of $0 \cdot 40 \mathrm{~mm}$. (approx.) a peripheral thickness of $0 \cdot 14 \mathrm{~mm}$., and an overall size of $13.50 \mathrm{~mm}$. This study was undertaken to evaluate the series of lenses for use in cases of aphakia.

\section{Material}

A group of $4^{8}$ patients ( 57 eyes involved) was chosen at random from referrals to the Contact Lens Department at Moorfields Eye Hospital. They were fitted and followed up for a 9-month period. The data obtained are set out in Tables I to V.

As might be expected, most of the patients were in the 50 to 70 -year age group and showed degenerative or senile cataract. The waiting list for cataract operations was about equal for each sex, but the referrals for contact lenses included a greater number of males (Tables I and II).

Table I Age distribution of 48 patients ( 32 males; 16 females)

\begin{tabular}{|c|c|}
\hline Age (yrs) & $\begin{array}{l}\text { No. of } \\
\text { patients }\end{array}$ \\
\hline $0-10$ & 5 \\
\hline I I -20 & 6 \\
\hline $21-30$ & 1 \\
\hline $3^{I-40}$ & 4 \\
\hline $4^{1-50}$ & 7 \\
\hline $5^{\mathrm{I}-60}$ & 12 \\
\hline $61-70$ & 10 \\
\hline $7^{1-80}$ & 3 \\
\hline Tota & 48 \\
\hline
\end{tabular}

Table II Type of cataract in 48 patients

\begin{tabular}{|c|c|c|}
\hline \multirow[t]{2}{*}{ Cataract } & \multicolumn{2}{|c|}{ Patients } \\
\hline & No. & Per cent. \\
\hline Congenital & 7 & 14.6 \\
\hline Traumatic & 9 & 18.7 \\
\hline Degenerative & 26 & $54 \cdot 2$ \\
\hline Complicated & 6 & 12.5 \\
\hline Total & 48 & 100 \\
\hline
\end{tabular}




\section{Findings}

The ocular refractive power for the average aphakic eye is + $13 \mathrm{D}$ sph. and +2 D cyl. (Tables III and IV). The keratometry shows a peak distribution between $7 \cdot 50$ and $7 \cdot 80$

Table III Ocular spherical com-

ponent in $5^{6 *}$ eyes

\begin{tabular}{|c|c|}
\hline Spherical power $(D)$ & No. of eyes \\
\hline Under $+7 \cdot 9$ & 1 \\
\hline+8 to 8.9 & 2 \\
\hline+9 to 9.9 & 2 \\
\hline+ Io to 10.9 & 4 \\
\hline$+I I$ to $I I \cdot 9$ & 8 \\
\hline+12 to $12 \cdot 9$ & 9 \\
\hline+13 to 13.9 & 10 \\
\hline+14 to 14.9 & 12 \\
\hline+15 to 15.9 & 3 \\
\hline+16 to 16.9 & 3 \\
\hline+17 and over & 2 \\
\hline Tot & $5^{6 *}$ \\
\hline
\end{tabular}

Table IV Cylinder component in $5^{6 *}$ eyes

\begin{tabular}{|c|c|c|}
\hline \multirow[t]{2}{*}{ Cylinder power $(D)$} & \multicolumn{2}{|l|}{ Cylinder } \\
\hline & Refraction & Keratometry \\
\hline +o to 0.9 & 6 & 9 \\
\hline+1 to $1 \cdot 9$ & 20 & I8 \\
\hline+2 to $2 \cdot 9$ & I 8 & 20 \\
\hline+3 to 3.9 & 9 & 5 \\
\hline+4 to $4 \cdot 9$ & 2 & o \\
\hline+5 to 5.9 & o & $\mathbf{I}$ \\
\hline+6 to $6 \cdot 9$ & I & I \\
\hline Total & $5^{6 *}$ & $* * 54$ \\
\hline
\end{tabular}

* One child (one eye involved) not included because opacity of the media made retinoscopy impossible

mm. (average $7.65 \mathrm{~mm}$.) in the horizontal direction, but a much wider range from 7.50 to $8.20 \mathrm{~mm}$. (average $7.85 \mathrm{~mm}$.) in the vertical direction. This is in keeping with clinical findings of a flatter vertical than horizontal meridian. Bearing in mind that the average keratometry of the normal eye is $7.80 \mathrm{~mm}$., this indicates that the horizontal keratometry reading is slightly steeper after cataract surgery. The ocular cylinder by refraction (average of $2 \mathrm{D}$ ) is directly related to the average by keratometry. This is to be expected, since the ocular refraction must bear a direct relationship to the keratometric power for the aphakic eye. The slight discrepancy in the readings is due to the spread of readings expected on a keratometer (Table V; Figs I and 2).

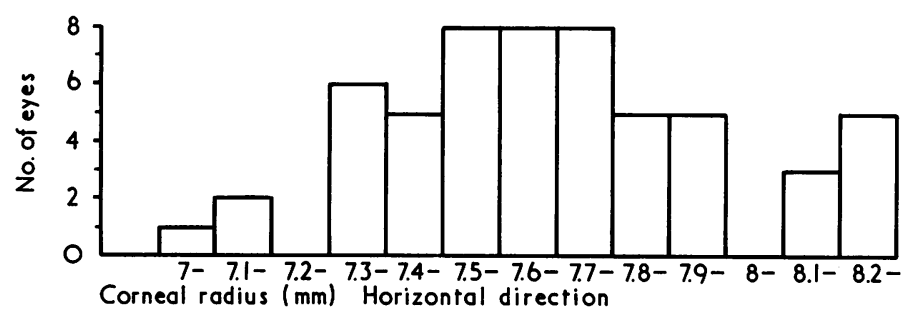

FIG. I Horizontal corneal radius (mm.) in 56 eyes ( 1 child not included)

Data from $3^{6}$ eyes (6/12 visual acuity or better with the gel lens and over-refraction) from the initial fitting visit were used to compare the keratometer corneal cylinder with the residual cylinder needed in the over-refraction (Fig. 3). For corneal cylinders up to $2 \mathrm{D}$, the residual cylinder needed is usually the same as the corneal cylinder, but above $2 \mathrm{D}$ a lower residual cylinder is needed in the over-refraction. Since the gel lens copies faithfully the curvature of the cornea, the residual astigmatism in the over-refraction relates to the effec- 


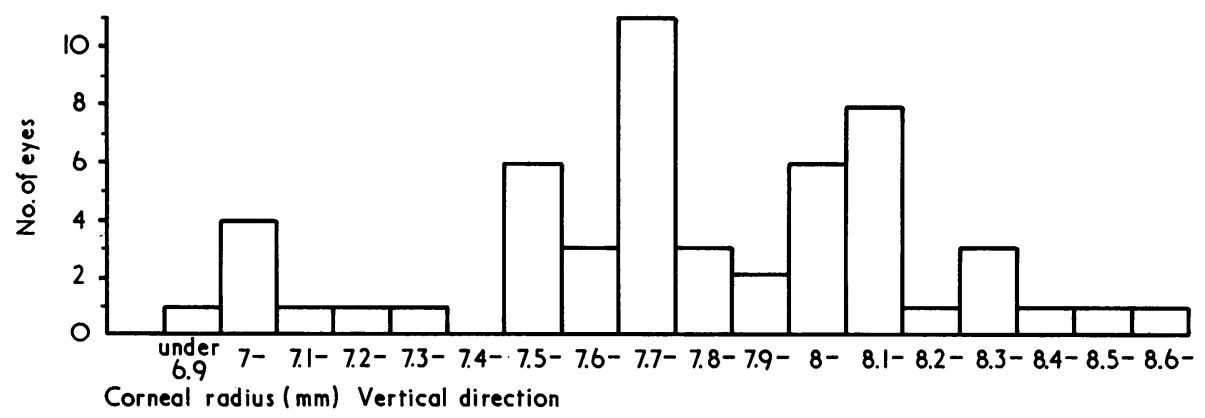

FIG. 2 Vertical corneal radius ( $\mathrm{mm}$.) in 54 eyes (I child not included; 2 readings too distorted for measurement)

Table V Corneal measurements $\left(5^{*}\right.$ eyes)

\begin{tabular}{|c|c|c|}
\hline \multirow{2}{*}{$\begin{array}{l}\text { Corneal radius } \\
(\mathrm{mm} .)\end{array}$} & \multicolumn{2}{|l|}{ Direction } \\
\hline & Horizontal & Vertical \\
\hline Under 7 & o & $\mathbf{I}$ \\
\hline $7 \cdot 0$ to $7 \cdot 09$ & $\mathbf{I}$ & 4 \\
\hline $7 \cdot 1$ to $7 \cdot 19$ & 2 & I \\
\hline $7 \cdot 2$ to $7 \cdot 29$ & o & I \\
\hline $7 \cdot 3$ to $7 \cdot 39$ & 6 & I \\
\hline $7 \cdot 4$ to $7 \cdot 49$ & 5 & o \\
\hline 7.5 to 7.59 & 8 & 6 \\
\hline $7 \cdot 6$ to $7 \cdot 69$ & 8 & 3 \\
\hline $7 \cdot 7$ to $7 \cdot 79$ & 8 & II \\
\hline $7 \cdot 8$ to $7 \cdot 89$ & 5 & 3 \\
\hline 7.9 to 7.99 & 5 & 2 \\
\hline 8.0 to 8.09 & o & 6 \\
\hline $8 \cdot 1$ to $8 \cdot 19$ & 3 & 8 \\
\hline 8.2 to 8.29 & 5 & I \\
\hline 8.3 to 8.39 & - & 3 \\
\hline 8.4 to 8.49 & - & I \\
\hline 8.5 to 8.59 & - & I \\
\hline 8.6 to 8.69 & - & I \\
\hline Total & $5^{6 *}$ & $* * 54$ \\
\hline
\end{tabular}

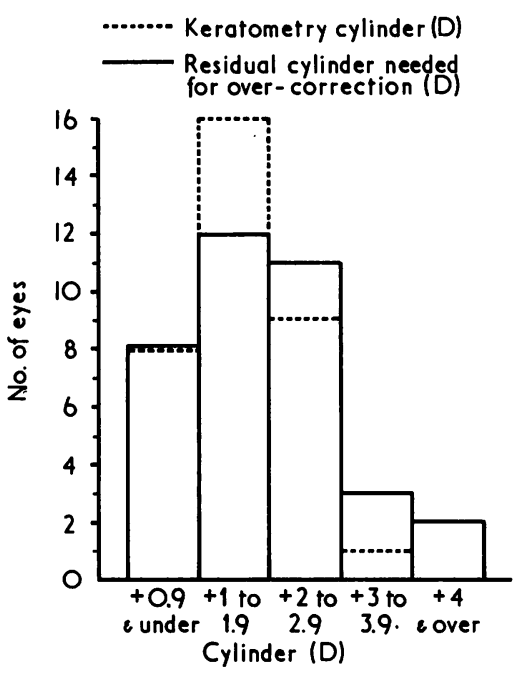

FIG. 3 Cylinder component $(D)$ in 36 eyes with 6/12 visual activity or better with over-correction at initial fitting.

tive power of the gel lens on the eye. Keratometry shows that, for gel lenses of these thicknesses $(0.35$ to $0 \cdot 60 \mathrm{~mm}$.), the radius difference in the cornea does not come through to the front surface of the gel lens. Therefore, despite the higher refractive index of PolyHEma ( $1 \cdot 44)$, the smaller power difference between the meridians on the front surface of the gel lens accounts for the lower over-correction cylinder. The higher corneal cylinders show a correspondingly smaller radius difference than the lower corneal cylinders.

The change of back curvature with power would mean steeper back curves for the low 
powers and flatter curves for the high powers. This is true only if the front curve remains constant. For the majority of patients +12 to $+16 \mathrm{D}$ were required (Table VI; Fig. 4) and it was noted that good centration was possible although there was no choice of fittings. The role of the thin peripheral portion must be of importance in this respect.

Table VI Back vertex power of gel lenses to nearest dioptre spherical in 57 eyes

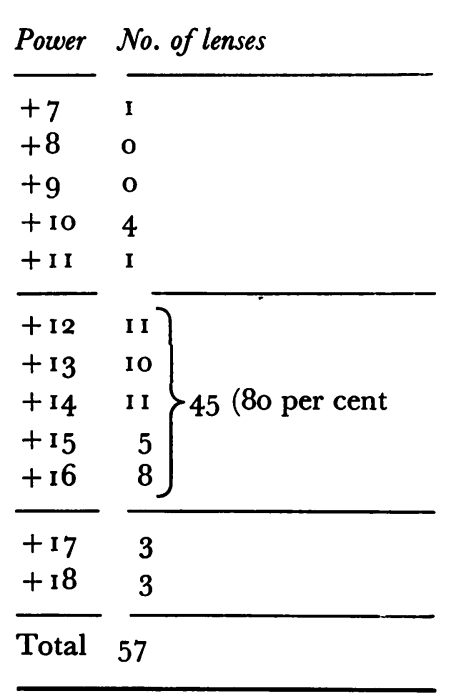

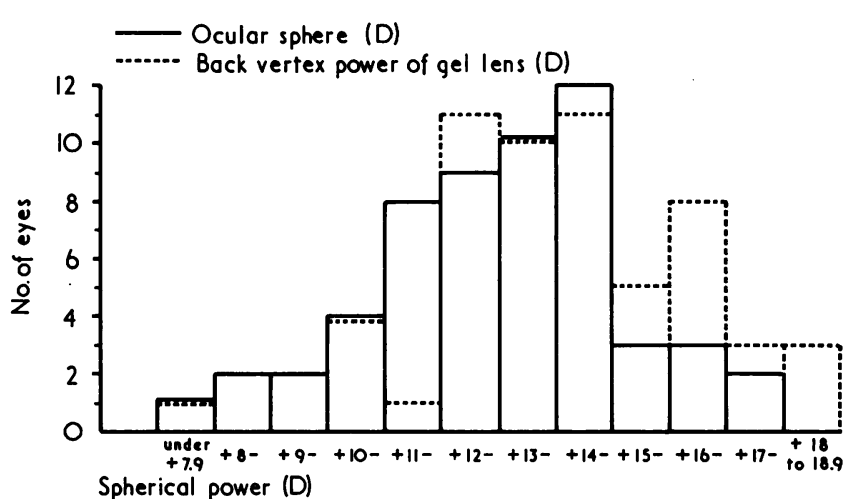

FIG. 4 Ocular spherical component $(D)$ and back vertex power of gel lens in 56 and 57 eyes respectively at initial fitting.

\section{Visual acuity}

A study of the visual acuities shows some important comparisons between spectacles, soft lenses, and soft lenses with over-correction (Fig. 5; Tables VII and VIII). Spectacle acuity gives 39 out of 57 (68 per cent.) with $6 / 7 \cdot 5$ or better. But with a soft lens alone only

Table VII Visual acuity with spectacles ( 57 eyes)

\begin{tabular}{|c|c|}
\hline No. of eyes & Corrected visual acuity \\
\hline 39 & $6 / 7 \cdot 5$ or better \\
\hline I I & $6 / 9$ to $6 / 18$ \\
\hline 7 & $6 / 24$ to $6 / 60$ or less \\
\hline
\end{tabular}

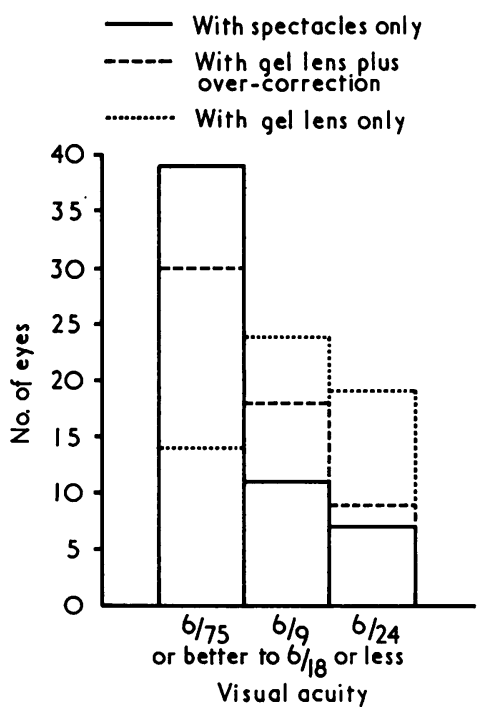

FIG. 5 Visual acuity with spectacles, with gel lens, and with both in 57 eyes at initial fitting 
Table VIII Visual acuity with contact lenses and lenses plus spectacles in 57 eyes initially and at follow-up

\begin{tabular}{|c|c|c|c|c|c|c|c|c|c|}
\hline \multirow{3}{*}{$\begin{array}{l}\text { Time of } \\
\text { testing }\end{array}$} & \multicolumn{6}{|c|}{ No. of eyes } & \multirow{3}{*}{$\begin{array}{l}\text { No. } \\
\text { seen }\end{array}$} & \multirow{3}{*}{$\begin{array}{l}\text { No. } \\
\text { due }\end{array}$} & \multirow{3}{*}{$\begin{array}{l}\text { Total } \\
\text { eyes }\end{array}$} \\
\hline & \multicolumn{2}{|c|}{$6 / 7.5$ or better } & \multicolumn{2}{|c|}{$6 / 9-6 / 18$} & \multicolumn{2}{|c|}{$6 / 24$ or less } & & & \\
\hline & Gel & $\begin{array}{l}\text { Gel plus } \\
\text { over-refraction }\end{array}$ & Gel & $\begin{array}{l}\text { Gel plus } \\
\text { over-refraction }\end{array}$ & Gel & $\begin{array}{l}\text { Gel plus } \\
\text { over-refraction }\end{array}$ & & & \\
\hline Initially & 14 & 30 & 24 & 18 & 19 & 9 & 57 & 0 & 57 \\
\hline After I $\mathrm{mth}$ & 7 & 20 & 17 & I5 & 17 & 6 & $4^{I}$ & I 3 & 54 \\
\hline After $3 \mathrm{mths}$ & 6 & 20 & 17 & I 7 & 23 & 9 & 46 & 7 & 53 \\
\hline After $6 \mathrm{mths}$ & 5 & 12 & 14 & I I & 7 & 3 & 26 & 19 & 45 \\
\hline After $9 \mathrm{mths}$ & 3 & 6 & 3 & 2 & 2 & o & 8 & 36 & 44 \\
\hline
\end{tabular}

I4 out of 57 (25 per cent.) achieved 6/7.5 or better. With a cylindrical over-correction, 30 out of 57 (53 per cent.) achieved $6 / 7 \cdot 5$ or better. Therefore, even with an over-correction, there is a fall of 13 per cent. in visual acuity with a soft contact lens. This is not so with hard [PMMA] lenses.

After 6 months, five out of 24 patients (2 I per cent.) achieved $6 / 7.5$ or better with the gel lens, whilst with the over-correction twelve out of 24 ( $5^{\circ}$ per cent.) achieved $6 / 7.5$ or better.

\section{Epithelial changes}

The epithelial changes seen on biomicroscopy are shown in Table IX. Many eyes were affected by more than one type of lesion; only the actual frequencies of each type are recorded. The numbers of eyes unaffected by any changes are also shown. Seven eyes remained unaffected after 9 months.

Table IX Epithelial changes revealed by biomicroscopy

\begin{tabular}{|c|c|c|c|c|c|c|c|}
\hline \multicolumn{2}{|c|}{ Time of examination } & \multicolumn{2}{|c|}{3 mths } & \multicolumn{2}{|c|}{6 mths } & \multicolumn{2}{|c|}{9 mths } \\
\hline & & No. & Per cent. & No. & Per cent. & No. & Per cent. \\
\hline \multirow[t]{4}{*}{ Lesion } & Punctate erosions & 9 & 22 & Io & 29 & 7 & 23 \\
\hline & Fine punctate keratitis & I I & 26 & I I & 32 & 12 & 27 \\
\hline & Microcysts & 12 & 29 & 7 & 20 & 5 & I6 \\
\hline & None & 18 & 43 & 13 & 37 & 7 & 23 \\
\hline \multicolumn{2}{|c|}{ Total eyes* } & 42 & & 35 & & $3^{I}$ & \\
\hline
\end{tabular}

* Some eyes showed more than one lesion

Punctate epithelial erosions were slight in degree and usually peripheral, though sometimes central. They were sparse and discrete and could be found in any quadrant of the cornea.

Punctate epithelial keratitis was also sparse. It occurred peripherally with a patchy distribution, and was non-progressive except in two patients, in whom wear was suspended after 9 months because of increasing central involvement. One patient suffered from chronic blepharitis and developed peripheral infiltrates of the staphylococcal type during wear; 
these infiltrates responded to local antibiotics. In the other patient a "bleb dystrophy" (Bron and Brown, I97I) was noted before a soft lens was worn, but remained unaltered during the period of wear. Bleb dystrophy has been associated with recurrent erosions and it may be noted that wear was discontinued because of the corneal changes and not for symptomatic reasons. The degree of punctate epithelial change was, in general, comparable with similar change in hard lens wearers.

A few epithelial microcysts were found in the central and mid-peripheral zones of the cornea as a not uncommon change. These frequently did not stain and were best seen by retroillumination. In general, they became less marked with longer wear. Coarse punctate keratitis and subepithelial changes were not found in any eye.

\section{Re-fitting}

Fewer eyes were examined at 9 months because some patients had been re-fitted with hard lenses, because of poor handling and frequent damage to their soft lenses (Table $\mathrm{X}$ ).

Table $\mathbf{X}$ Re-fitting required (57 eyes)

\begin{tabular}{lllll}
\hline Time of examination & No. of eyes & Re-fitted PMMA & $\begin{array}{c}\text { Total not } \\
\text { re-fitted }\end{array}$ \\
\cline { 1 - 1 } Initial & 57 & 3 & 54 \\
After I mth & 54 & I & 53 \\
After 3 mths & 53 & 8 & 45 \\
After 6 mths & 45 & o* & 44 \\
After 9 mths & 44 & I & 43 \\
\hline
\end{tabular}

* Re-fitted with another soft lens

\section{Wearing pattern}

Most of the patients achieved a good wearing pattern of io hours or more (Table XI), but the total number wearing the lenses decreased progressively from 54 to 44 in 9 months.

Table XI Wearing patterns

\begin{tabular}{|c|c|c|c|}
\hline Hours of wear & After 3 mths & After 6 mths & After 9 mths \\
\hline I-6 & 4 & I & o \\
\hline $7-10$ & 3 & I & o \\
\hline $11-15$ & 14 & 8 & 2 \\
\hline $16+$ & 22 & 14 & 6 \\
\hline Total recorded & 43 & 24 & 8 \\
\hline No. due & 7 & 19 & 36 \\
\hline Not recorded & 3 & 2 & 0 \\
\hline Total eyes & 53 & 45 & 44 \\
\hline
\end{tabular}

For a similar group fitted initially with hard lenses, no soft lenses being available, 46 eyes commenced wear and after 9 months 26 were still wearing them. The soft lens, therefore, is better tolerated, and gives a visual acuity of $6 / 7.5$ or better for approximately 50 per cent. 
of the patients, the cost being about two lenses per patient for each eye in a 9-month period (Table XII).

Table XII No. of lenses used

\begin{tabular}{ll}
\hline Total lenses issued & 95 \\
\cline { 1 - 2 } $\left.\begin{array}{ll}\text { Lenses damaged } & 23 \\
\text { Lenses with surface defects } & 15\end{array}\right\}^{8}$ \\
\hline
\end{tabular}

\section{Conclusion}

The soft contact lens is, both economically and optically, a worthwhile form of treatment for the aphakic patient as compared with the spectacle lens.

\section{References}

BRON, A. J., and BROWN, N. A. (197I) Trans. ophthal. Soc. UK., 91, I 3

WICHTERLE, O., and LIM, D. (1960) Nature (Lond.), 185, I I 7 